\title{
The Clinical Educators' Experience of Replacing Physiotherapy Student Clinical Education Time with Simulation
}

\author{
*Julia Blackford ${ }^{a}$, Jennifer Alison ${ }^{a}$, Lindy McAllister ${ }^{a}$, \& Gillian Nisbet ${ }^{a}$ \\ a: University of Sydney, Australia
}

\begin{abstract}
Simulation is increasingly being utilised to replace part of physiotherapy clinical education. This pilot study aimed to investigate clinical educators' perspectives of physiotherapy student preparedness for clinical placement. A mixed-methods study using a sequential explanatory design was undertaken. Clinical educators completed questionnaires after supervising two groups of students, one that had one week of simulation followed by a fourweek placement $(1+4$ week group) and the other a full 5 -week placement in a clinical setting $(0+5$ week group). Both groups of clinical educators rated students' preparedness to commence placement. Clinical educators in the $1+4$ week group were also interviewed after the placement. Descriptive statistical analysis of the questionnaire data found no notable difference in the perceived preparedness of the students between groups. Clinical educator interviews revealed aspects of placement preparedness for students in the $1+4$ week model that were considered better when compared to students previously supervised who had not undertaken simulation. Educators reported student outcomes at the end of the placement equivalent to those of students they had supervised previously who had the full five weeks in a clinical setting. However, the clinical educators also reported that replacing the first week of a clinical placement with simulation resulted in students not being at the expected level at the beginning of the second week of placement. Consequently, educators felt pushed to accelerate the learning experience to make up for the reduced clinical time. Further investigation is required into the models of simulation as replacement for clinical placement time.
\end{abstract}

\section{Keywords: clinical educator; physiotherapy; simulation}

\section{Introduction}

Simulation has increasingly been utilised in the education of allied health students. It provides the opportunity to expose students to settings that closely resemble the real clinical environment but removes the stress of dealing with real patients (Bokken et al., 2008; Gordon et al., 2001; Kneebone \& Nestel, 2005). Students are able to practise their clinical skills in a safe, controlled learning environment, bridging the gap between academic and clinical settings. In Australia there has been a significant increase

*Corresponding Author: Julia Blackford, Faculty of Medicine and Health, School of Health Sciences, Cumberland Campus, University of Sydney, PO Box 170, Lidcombe, NSW 1825, Australia Email: julia.blackford@sydney.edu.au

Journal URL: https://publications.coventry.ac.uk/index.php/pblh

Blackford, J., Alison, J., McAllister, L., \& Nisbet, G. (2020). The clinical educators' experience of replacing physiotherapy student clinical education time with simulation. International Journal of Practice-based Learning in Health and Social Care, 8(1), 60-72. https://doi.org/10.18552/ijpblhsc.v8i1.554 
in the number of physiotherapy programs offered by universities (National Health Workforce Taskforce, 2008). The resulting increase in overall student numbers has increased the demand for clinical placements and has led to universities exploring quality alternatives to the traditional placement model. In 2014, Health Workforce Australia funded a large-scale national project in physiotherapy to investigate the use of simulation to replace clinical placement time and increase placement capacity (Wright et al., 2015). The model of simulation investigated used standardised patients in a simulated clinical setting. Standardised patients are actors trained to play the role of patients with specific conditions.

In the traditional clinical placement model, physiotherapy students are supervised and assessed by clinicians (referred to as clinical educators). In Australia, placements generally consist of students attending a clinical site for five weeks, at the end of which they are assessed using the Assessment of Physiotherapy Practice (APP) tool. The APP is a national assessment tool that measures students' performances against new graduate competencies (Dalton et al., 2011; Dalton et al.,2012) as set out by the Australian Physiotherapy Council in the Physiotherapy Practice Thresholds document (Australian Physiotherapy Council, 2015). Clinical educators are required to supervise students as part of their usual duties so students ideally need to be well prepared and have some level of confidence to start placement. According to Chipchase et al. (2012), clinical educators indicated that students should commence placement with a sound theoretical knowledge, a knowledge of basic conditions and treatment principles, and the ability to be self-directed in their learning. Improved student preparedness is one of the aims of simulation and it has been shown to be effective in achieving this from the student perspective (Blackstock et al., 2013; Blackford et al., 2015).

Studies have investigated the impact on student confidence to undertake placement and end-of-placement assessment outcomes when the first week of the 5-week clinical placement was replaced by simulation (i.e. the 1+4 model) (Blackford et al., 2015; Blackstock et al., 2013; Watson et al., 2012). These studies found that not only were physiotherapy students more confident to undertake placement after a week of simulation, but also that there was no difference in scores achieved in the final assessment of these students, indicating that from the student perspective simulation could be used to replace clinical placement time with no detriment to learning outcomes. To date no studies have reported the clinical educators' experiences of supervising students who have part of their clinical placement replaced by simulation. For such a model to be successful it is important that all stakeholders are considered.

This pilot study was conducted to gain insight into the experience of clinical educators when the first week of clinical placement was replaced by simulation, and to determine the feasibility of implementing and evaluating this model on a larger scale. This study builds on our related research exploring student perspectives of the model and its impact on learning outcomes (Blackford et al., 2015). The aim of this current study was: 1) to compare, via questionnaire, the clinical educator experience of supervision of graduate entry masters students (i.e. students completing the two-year entry level postgraduate physiotherapy course) whose first week of placement was replaced with simulation (1+4 week group) compared to clinical educators who had students for the full 5 weeks of placement ( $0+5$-week group); and 2) to determine, via focused interviews, the opinions of clinical educators of students' preparedness and performance on clinical placement of the $1+4$ week group compared to students they had previously supervised in a 5-week placement.

\section{Method}

\section{Design}

This study used mixed methods with an explanatory sequential design (Creswell \& Plano Clark, 2011), to explore participants' experiences of student preparedness for placement. The initial quantitative arm of the study consisted of an independent group, non-randomised study comparing questionnaire responses of an intervention group (clinical educators who supervised students who received one week of clinical simulation followed by a 4-week placement, i.e. $1+4$ week group) with a control group (clinical educators who supervised students for a 5-week placement, i.e. 0+5 week group). In the subsequent qualitative arm, semi-structured interviews were conducted with the clinical educators of the $1+4$ week group who supervised students after the one week of simulation (i.e. 1+4 week group). This was done at the end of the students' placement to gain further insight into the questionnaire responses. For comparison, these clinical educators were also prompted to draw on their previous experiences with students they had supervised in the past who had not undertaken simulation. 


\section{Participants}

The participants in this study were physiotherapy clinical educators working in public or private hospitals who were scheduled to supervise physiotherapy students undertaking their first clinical placement in an acute or rehabilitation setting as part of the graduate entry masters course at a large Australian university. All clinical educators had previous experience in supervising physiotherapy students. Participation was voluntary. The study was approved by the Ethics Committee of the University of Sydney and all participants provided informed consent.

\section{Procedure}

Convenience sampling was used to recruit participants (Moore, 1999). Twelve participants were considered appropriate for this small pilot study. Individual clinical educators were approached by the university academic responsible for coordinating the clinical placements and asked if they were willing to supervise students in the $1+4$ week group. Once the target sample size of six was reached for the $1+4$ week group, other clinical educators taking students from the same cohort were invited to participate as part of the $0+5$ week group until six were recruited. Demographic data were not collected due to the process of participant recruitment through convenience sampling and being a pilot study.

Students were randomly allocated to undertake either an acute or a rehabilitation placement. They were then randomly allocated to their corresponding placements utilising the university's electronic placement allocation system. The sites offering the $1+4$ week model and $0+5$-week model of placement were grouped together in the placement allocation system allowing students to be randomly assigned a placement model. Students in the simulation group completed the $1+4$ week model of placement $(1+4$ week group), while those in the control group completed five weeks of clinical placement $(0+5$ week group). The students allocated to the $1+4$ week group attended one week of a clinical simulation in the management of patients in either an acute or rehabilitation setting followed by four weeks of clinical placement in the same clinical area, as described by Blackford et al. (2015). The 0+5 week group attended five weeks of clinical placement in either an acute or rehabilitation setting.

The clinical educators of the $1+4$ week group provided placements in the same area of practice to which students were exposed during the simulation week (i.e. acute or rehabilitation). They commenced supervising the students after one week of simulation (i.e. equivalent to week two of the five-week placement). The clinical educators were provided with minimal information about the students' learning opportunities during the week of simulation. This was done intentionally to ensure that prior knowledge of what students had undertaken as preparation in the simulation week did not influence the clinical educators' observations and assessments of the students.

\section{Data Collection Methods}

\section{Quantitative}

The data collection sequence has been represented in Figure 1.

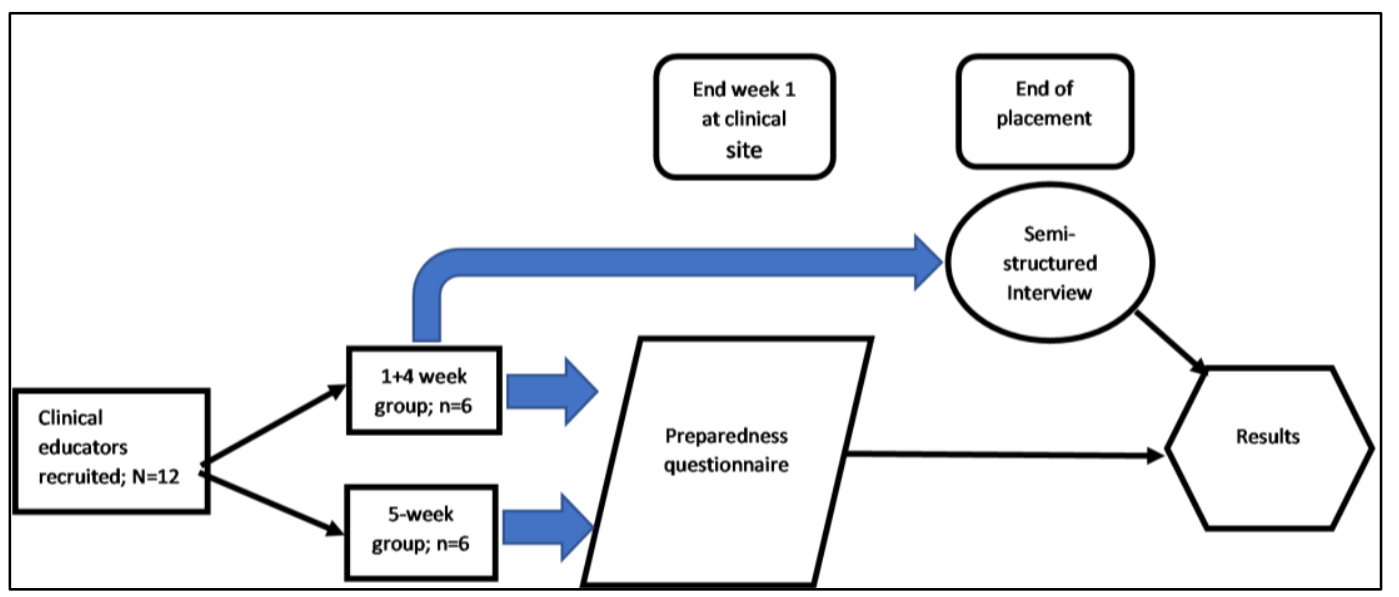

Figure 1: Data collection process 
Clinical educators in both $(1+4$ week and $0+5$ week $)$ groups were asked to complete a questionnaire (Table 1) developed for this project to gauge how prepared the clinical educators felt the students were for their placement. The questionnaire consisted of 14 items rated on a 4-point Likert scale. The items were based on the Australian Physiotherapy Council Standards (Australian Physiotherapy Council, 2006). Face validity was considered by drawing on the researchers' experience as educators (Patton, 2002). The questionnaire items were initially developed by the first author. These items were then reviewed by the researchers and the academics implementing the simulation week for item ability to capture student performance. Reviewer feedback was incorporated into the final questionnaire. All reviewers had previous experience as clinical educators so were able to draw on this experience when reviewing items.

The clinical educators were asked to rate how prepared they felt the students were in their professional and clinical skills. The questionnaire was completed at the end of the first week of the student's placement in the real clinical setting in both groups (i.e. end of week one for the $0+5$ week group and end of week two for the $1+4$ week group).

Table 1: Student's preparedness for clinical placement questionnaire

\begin{tabular}{|c|c|c|c|c|}
\hline $\begin{array}{l}\text { At what level do you feel the student is } \\
\text { able to: }\end{array}$ & $\begin{array}{l}1=\text { below } \\
\text { acceptable }\end{array}$ & $\begin{array}{l}2= \\
\text { acceptable }\end{array}$ & $\begin{array}{l}3= \\
\text { good }\end{array}$ & $\begin{array}{l}4= \\
\text { excellent }\end{array}$ \\
\hline 1. Communicate with patients & & & & \\
\hline $\begin{array}{l}\text { 2. Demonstrate appropriate professional and } \\
\text { ethical behaviour }\end{array}$ & & & & \\
\hline $\begin{array}{l}\text { 3. Utilise manual handling skills with } \\
\text { patients }\end{array}$ & & & & \\
\hline $\begin{array}{l}\text { 4. Accept and respond to constructive } \\
\text { feedback }\end{array}$ & & & & \\
\hline $\begin{array}{l}\text { 5. Use your problem-solving skills in the } \\
\text { clinical setting }\end{array}$ & & & & \\
\hline $\begin{array}{l}\text { 6. Utilise your capacity for independent } \\
\text { critical thought and self-directed learning }\end{array}$ & & & & \\
\hline $\begin{array}{l}\text { 7. Demonstrate ability and confidence to } \\
\text { participate effectively in collaborative } \\
\text { learning as a team member, while respecting } \\
\text { individual differences }\end{array}$ & & & & \\
\hline 8. Plan work and use your time effectively & & & & \\
\hline $\begin{array}{l}\text { 9. Demonstrate flexibility/adaptability in the } \\
\text { workplace }\end{array}$ & & & & \\
\hline $\begin{array}{l}\text { 10. Assess patients' abilities, problems and } \\
\text { needs }\end{array}$ & & & & \\
\hline $\begin{array}{l}\text { 11. Develop a physiotherapy intervention } \\
\text { plan to meet defined goals }\end{array}$ & & & & \\
\hline $\begin{array}{l}\text { 12. Implement physiotherapy intervention } \\
\text { strategies }\end{array}$ & & & & \\
\hline $\begin{array}{l}\text { 13. Set up the environment to maximise the } \\
\text { effectiveness of their assessment and } \\
\text { treatment of the patient }\end{array}$ & & & & \\
\hline $\begin{array}{l}\text { 14. Appropriately apply knowledge and } \\
\text { skills to patients }\end{array}$ & & & & \\
\hline
\end{tabular}

\section{Qualitative}

Semi-structured telephone interviews were conducted with the six clinical educators in the $1+4$ week group. The interview was conducted by the first author (JB) at the completion of the student placement. 
A topic guide was developed to promote consistency of the data elicited (Table 2). Topics covered in the interview included student's overall preparedness for placement, preparedness in professional and clinical skills at the beginning and end of the students' placements, and feedback or suggestions for improvement in the simulation program. The interviews ran for 8 to 12 minutes, reflective of the limited available time of clinical educators. If placement supervision had been shared with more than one clinical educator then both were interviewed together. All interviews were audio recorded (with consent from the clinical educators) and transcribed by an external transcription service. Interviews that included more than one clinical educator were transcribed with each individuals' comments appearing in new paragraphs. To protect privacy, no names were recorded during the interviews.

Table 2: Topic guide for semi-structured interviews

\begin{tabular}{|c|c|}
\hline Q1 & $\begin{array}{l}\text { How did the students who had the week of simulation compare at the beginning of their } \\
\text { placement with previous students you have supervised who did not have simulation in terms } \\
\text { of performance of their: } \\
\text { 1. Professional and generic skills? } \\
\text { 2. Clinical skills? }\end{array}$ \\
\hline $\mathrm{Q} 2$ & $\begin{array}{l}\text { How did the students who had the week of simulation compare at the end of their placement } \\
\text { with previous students you have supervised who did not have simulation in terms of } \\
\text { performance of their: } \\
\text { 1. Professional and generic skills? } \\
\text { 2. Clinical skills? }\end{array}$ \\
\hline Q3 & What were your expectations of the students after a week of simulation? \\
\hline Q4 & $\begin{array}{l}\text { What was your perception of the students' preparedness for the clinical setting after a week of } \\
\text { simulation? }\end{array}$ \\
\hline Q5 & Do you have any other comments/feedback? \\
\hline
\end{tabular}

\section{Data Analysis}

\section{Quantitative}

Data were analysed using IBM SPSS Statistics (version 22) software. Due to the small sample size and high risk of type II error, statistical analysis was not considered appropriate, although descriptive analysis is presented in Table 3.

\section{Qualitative}

Categorical analysis to identify major categories of meaning in the data (Patton, 2002) was conducted on the interview transcripts, beginning with initial coding conducted manually by the first author. The coding was then discussed with the second author to achieve consensus on codes. The first author then reviewed all transcripts against the revised codes. Codes were clustered into overarching categories by the first author and then discussed with all authors in order to achieve consensus on the final set of categories. Quotes were identified to illustrate each category. Triangulation of the quantitative and qualitative data through comparison of the outcomes formed the overall results.

\section{Results}

Twelve clinical educators were recruited (two males, 10 females). Four sites comprising a total of six clinical educators supervising the $1+4$ week group, and five sites comprising a total of six clinical educators supervising students in the $0+5$ week group agreed to participate. Each group supervised 16 students in total. One participant in the $0+5$-week group failed to complete the questionnaire. All six clinical educators from the $1+4$ week group participated in the semi-structured interview. 


\section{Quantitative}

The median and interquartile ranges are reported in Table 3 and show no clear evidence that one model is preferable to another. There is some divergence in questions 7 (relating to collaborative learning and teamwork) and 9 (relating to flexibility and adaptability to the workplace), with the $0+5$ week model scoring higher; and in questions 11 (relating to developing an intervention plan) and 13 (relating to setting up the environment), with the $1+4$ week model scoring higher.

Table 3: Results of clinical educator questionnaire by group for student preparedness

\begin{tabular}{|c|c|c|}
\hline Question & $\begin{array}{l}\text { 1+4 week } \\
\text { Median (IQR) }\end{array}$ & $\begin{array}{l}\text { 0+5 week } \\
\text { Median (IQR) }\end{array}$ \\
\hline & $n=6$ & $n=5$ \\
\hline Q1. Communicate with patients & $2.0(1.0-3.0)$ & $2.0(1.0-3.0)$ \\
\hline $\begin{array}{l}\text { Q2. Demonstrate appropriate professional and ethical } \\
\text { behaviour }\end{array}$ & $3.0(2.5-3.5)$ & $3.0(1.5-4.0)$ \\
\hline Q3. Utilise manual handling skills with patients & $2.0(0-0)$ & $2.0(1.0-3.0)$ \\
\hline Q4. Accept and respond to constructive feedback & $3.0(2.5-3.5)$ & $3.0(2.0-4.0)$ \\
\hline Q5. Use their problem-solving skills in the clinical setting & $2.0(1.8-2.3)$ & $2.0(1.0-3.0)$ \\
\hline $\begin{array}{l}\text { Q6. Utilise their capacity for independent critical thought } \\
\text { and self-directed learning }\end{array}$ & $2.0(0.8-3.3)$ & $2.0(1.0-3.0)$ \\
\hline $\begin{array}{l}\text { Q7. Demonstrate ability and confidence to participate } \\
\text { effectively in collaborative learning as a team-member, } \\
\text { while respecting individual differences }\end{array}$ & $2.0(1.5-2.5)$ & $3.0(2.0-4.0)$ \\
\hline Q8. Plan work and to use time effectively & $2.0(1.0-3.0)$ & $2.0(1.0-3.0)$ \\
\hline Q9. Demonstrate flexibility/adaptability in the workplace & $2.0(0.75-3.25)$ & $3.0(1.5-4.0)$ \\
\hline Q10. Assess the patients' abilities, problems and needs & $2.0(0-0)$ & $2.0(0.5-3.5)$ \\
\hline $\begin{array}{l}\text { Q11. Develop a physiotherapy intervention plan to meet } \\
\text { defined goals }\end{array}$ & $2.0(1.5-2.5)$ & $1.0(-0.5-2.5)$ \\
\hline Q12. Implement physiotherapy intervention strategies & $2.0(1.0-3.0)$ & $2.0(1.0-3.0)$ \\
\hline $\begin{array}{l}\text { Q13. Set up the environment to maximise the effectiveness } \\
\text { of their assessment and treatment of the patient }\end{array}$ & $2.0(0-0)$ & $1.0(1.0-3.0)$ \\
\hline $\begin{array}{l}\text { Q14. Appropriately and effectively apply knowledge and } \\
\text { skills to patients }\end{array}$ & $2.0(1.8-2.3)$ & $2.0(0-4.0)$ \\
\hline
\end{tabular}

Inferential statistics did not clarify any differences between the models so were not reported

\section{Qualitative}

Six overarching categories were identified from the iterative data analysis. These were: 1) preparedness of students; 2) expectations of (i) the students and (ii) simulation; 3 ) perception of time available for students to achieve competence; 4) impact of lack of prior knowledge about the content of the simulation week; 5) no difference in student outcomes by end of the placement; and 6) general feedback and suggestions for improvement. Representative quotes which exemplify the range of clinical educator responses are presented below for each category.

\section{Preparedness of students}

The clinical educators felt that the students undertaking a week of simulation were better prepared for their experience in terms of professional skills than students they had supervised previously who had not 
had the simulation week. Specifically, the clinical educators felt that the students displayed a greater willingness to learn and engage in self-directed learning. The students displayed increased ability to work with their peers to solve problems which reduced the load for the clinical educators.

I would say that overall their keenness to learn and the concept of having to go look things up and all that sort of thing seemed to come more naturally to them. So I would say overall their professional behaviour was probably a little bit ahead of where the average students would be in that starting week. Participant 1

Probably the biggest difference was I think just their familiarity with each other and probably the way we saw that was they just more immediately went in to group work and group brainstorming. Participant 2

There were mixed reports on how well-prepared students were to apply their clinical skills. Some clinical educators felt that there was no difference compared with students they had supervised previously and some felt the students were slightly better prepared to apply their clinical skills. Clinical educators did not feel that the students were at the level they would expect had the students undertaken the first week of placement at their site and felt that the simulation students were behind students who they would normally take on a five week placement.

They were better than the usual starting of a unit in terms of being able to go and take a patient history, in terms of really being able to deal with them and do their clinical reasoning in the actual working format. I think if I was to compare week two [of a standard five-week placement], to week two [of the 1+4 week group] so having done the first week in their workplace as opposed to simulation, I would say they're a little bit behind. Participant 1

\section{Expectations}

The category of expectations fell into two sub-categories: 1) the expectations the clinical educators had of the students, and 2) the expectations the clinical educators had of what the simulation week would deliver.

(1) Expectations of student performance

Clinical educators expected that, following a week of simulation, students would be ready to commence their placement at the same performance level of a week-two student undertaking the traditional placement. However, this expectation was not always met.

... their physical handling skills weren't any different to other students. I might have perceived that their physical handling skills might have been better than students who hadn't done the simulation but they weren't. Participant 3

(2) Simulation

The clinical educators had expectations of what would be delivered during the simulation week, usually based on the types of learning experiences they provide the students if they have the students from week one. Several of the clinical educators commented that these expectations were not met.

... it wasn't obvious in that first week that we had them that they had done the week of simulation. In fact, one of them commented at the end of the clinical that they would have liked more manual handling practice and skills in that first week of the clinical here which was interesting because I would have thought that was part of the purpose of the simulation but obviously they hadn't, that particular student hadn't, gained those skills or picked that up in that first week. Participant 3 


\section{Perception of less time}

Clinical educators felt they had less time for the students to achieve competency. The clinical educators were conscious that they had one less week to work with the students and felt pressure to achieve the same outcomes:

Certainly, by the end of the four weeks that we'd had with them they'd certainly caught up and they were at the same standard that I'd expect them to be but I think we had to do a lot more work in that second week to catch them up to where they needed to be. Participant 3

... I was only going to have four weeks to get them competent rather than five. I guess that was my only concern, that if we had a student who was struggling, I'd only have that fourweek period. Participant 1

During the first few days when students commenced placement at the clinical site it took time for the students to become familiar with the setting, including specific requirements around procedures and practices such as documentation. The clinical educators also required time early in the placement to get a sense of the students' knowledge and capabilities in order to decide if they were able to manage patients independently.

It was the environment, becoming familiar with their surroundings and how things worked here ... Participant 4

Maybe it's also us getting used to the students as well because we're not familiar with them. We don't know how - like just meeting them the first day in week two, normally you would have had the week of familiarisation with the students as well so you would know whether this person is going to go ahead and take a risk or not. Participant 5

\section{Lack of prior knowledge of the simulation week content}

The clinical educators found that not being informed of the details of the simulation week made it difficult for them to achieve continuity from the first week of simulation to the second week starting in the clinical setting:

I was able to get a little bit of an insight into what they'd done in the simulation week but not much and perhaps if I had known a bit more it may have been helpful for me to relate what we were doing in the second week to what they did in the simulation. Participant 2

\section{No difference in student outcomes}

All the clinical educators interviewed agreed that by the end of the 5-week placement there was no perceived difference in the level of achievement between the students who had the week's simulation and students they had supervised previously who had attended the placement for the full five weeks. This was in relation to both their professional and clinical skills:

Not perceivably [any difference], no, there wasn't any marked difference between that group of students to previous groups of students that we've had. Participant 3

\section{Feedback and suggestions for improvement}

At the conclusion of the interview the participants were asked for their overall feedback on the week of simulation and suggestions for improvement. Feedback included that during the simulation week the students could spend more time with patients practising skills such as manual handling, and reading patient medical records and documentation to better prepare them for placement. All the clinical educators felt that the overall concept of students undertaking simulation was positive. One commented that the possibility of having students for one week less would relieve some of the pressure of taking consecutive placements and may encourage clinical educators to take more placements: 
For me personally I think it could work in the long run and I think in some ways as an 'acute' educator it would make me more likely to take more consecutive pracs [practical placements] if I knew I was going to get the odd week break. Participant 1

Others liked the concept of simulation but recommended that it may be best utilised as part of the academic teaching program rather than taking time away from placement in the clinical setting:

... simulation week might be better placed more as a uni [university] focus thing rather than taking it from the clinical, a way of tying in uni [university] and the clinical situation rather than taking away from their time on the clinical. Participant 3

\section{Discussion}

This study investigated the impact of replacing the first week of clinical placement with simulation on the preparedness of graduate-entry masters physiotherapy students for the subsequent four-week clinical placement, from the clinical educators' perspective. The key findings from the questionnaire completed by all the clinical educators were that there were no clear differences evident between the $1+4$ and the $0+5$ week groups at the end of the students' first week at the clinical placement site. The interviews undertaken at the end of the clinical placement identified some areas in which clinical educators perceived students in the $1+4$ week group to be better prepared for clinical placement. These areas were: the ability to communicate with patients, to be self-directed in their learning, and to engage in peer learning. However, these students were not considered to be at the same level of a student who had undertaken their first week of placement at the clinical site in other areas such as manual handling, note writing and time management. These latter deficits created a level of stress for educators who felt they needed to accelerate student progression in the 1+4 week group. At the end of placement, clinical educators considered that students in the 1+4 week group had achieved the same level of competency as those they had previously supervised for the full five weeks

Chan (2002) describes the complex social context in which clinical education occurs. Students are required to adjust to unpredictable environmental conditions, while combining cognitive, psychomotor and affective skills to respond to individual client needs while ensuring client safety. During the first part of a placement students need to become familiar with a new environment, which may often be confronting if not experienced previously (Houghton et al., 2013). It also takes time for students to become familiar with practices and procedures required at different sites, some of which may differ from what has been taught in the academic setting (Dutton \& Sellheim, 2017). This was a factor frequently raised by the clinical educators in their interviews. In a study investigating the experience of radiography students on their first clinical placement, students identified that speaking with other clinicians, dealing with very ill patients, and manoeuvring around the environment as particularly challenging aspects of the transition into the clinical setting (Hyde, 2015). Time is needed for adjustment to a new clinical environment and should be taken into account when utilising simulation as a replacement for clinical time. Clinical educators of the $1+4$ week group commented that as they had the students for less time they often felt that they were required to work harder to get the students to an equivalent level as students in past 5-week placements. The perception of less time for students to achieve standards meant that educators felt that the early weeks of the placement were more intensive, to compensate for the shorter time they had the students at their site.

There is a period early in placement when the clinical educator needs to gain information about students' level of background knowledge and clinical skills in order to make decisions about what they feel the students can do independently (Jette et al., 2007). Despite the students having had a week of simulation experience, the clinical educators were not able to gauge the level of the students' abilities and had to take time to make this assessment for themselves. This issue was compounded by the method used in this study where the clinical educators were not informed of the students' prior experiences or achievements in simulation. The clinical educators are ultimately responsible for the management and safety of the patients they assign to students, so they need to be confident in students' capabilities (Jette et al., 2007). This process of verification of a student's capabilities and level of safety would usually commence during the first week of placement. When the students had their first week in a simulation environment the clinical educators made these assessments about the students' abilities in the second week. This resulted in the clinical educators possibly restricting the students more than may have been necessary given their week of practice in simulation. Clear expectations about what the simulation setting can provide for 
students during the first week of placement, and the expectations the clinical educators have of what should be covered, need to be congruent in order for the transition from simulation to clinical placement to be effective. This is consistent with Kneebone et al. (2004) who found that for simulation to be exploited to its full potential, it must be used alongside and linked closely with clinical practice. These findings suggest that further investigation into the impact of conveying details to the clinical educators of the specifics of the simulation week on their ability to transition the students into the clinical setting is required.

The overall consensus from the clinical educators was that despite having the students for one week less, the level of competency by the end of the placement was no different from that of students they had taken previously on their five-week placement. This finding is supported by the outcome in the student arm of this research which found no difference in the final assessment of the students in the $1+4$ model with those in the $0+5$ week model (Blackford et al., 2015). However, the interviews with clinical educators revealed perceptions that they had to do more work early in the placement to get the students to the required level by the end of the placement.

Skills acquisition during simulation focuses on professional and clinical skills related to the clinical area (Blackford et al., 2015; Blackstock et al., 2013; Watson et al., 2012). Results of the qualitative data from this study suggested that learning skills such as self-directed and peer learning are practised and enhanced through the simulation experience. This was also reported in the student outcomes study (Blackford et al., 2015) which found that the students regarded simulation as providing opportunities to engage in positive workplace learning experiences such as procedural practice, using feedback to adjust practice and selfreflection. It may be that the students' better preparation to engage in independent and peer learning activities allowed them to progress more quickly through the early adjustment stage of the placement at the clinical site.

The clinical educators generally perceived the concept of students undertaking simulation prior to their clinical placements as positive. They acknowledged that the students were, overall, better prepared to commence the placement, but that their technical skills were lower than the expected level at the beginning of week two of a traditional five-week placement. There were suggestions that simulation would be better undertaken during the students' academic units as part of the practical teaching. Another suggestion was that simulation be used as preparation for placement rather than replacing clinical placement time. The perception that the students had to put in more work during the initial stages of the placement, in order to reach the level of a student who had been on placement in the clinical setting for the full five weeks, was raised as the major concern of the clinical educators about taking students after simulation.

\section{Limitations}

A limitation to this study was that it was a pilot study and as such had a small number of participants. We suggest that a larger study with greater sample size be undertaken as future research in order to have sufficient quantitative data to conduct inferential statistical analysis. Full validation of the questionnaire was not conducted for this pilot study, rather utilising face validity. This may have had implications for the responses to the questionnaire. Furthermore, the questionnaire was completed at the end of the first week that clinical educators had with the students and the interviews were conducted at the conclusion of the placement. This meant that the clinical educators were reflecting on the students' performances at different points in time and therefore their perceptions of what the students were capable of may have changed over time. The limited time for the interviews meant that the questions were focused on the broad perceptions that the clinical educators had of the students' preparedness. We suggest future studies are designed to collect more detailed information during the interviews to supplement the questions on the questionnaire. The clinical educators in this study were not blinded to whether the students had completed a simulation week, which may have influenced their responses.

\section{Conclusion}

This pilot study suggests that, from the perspective of the clinical educators, students can benefit from exposure to simulation prior to starting a clinical placement as they are better prepared to commence their placement in some areas of their practice. Importantly, educators in our study perceived student 
competence by the end of placement to be comparable to the traditional five-week placement model. However, our study has identified a specific issue that needs to be addressed to maximise the learning potential of simulation in replacing placement time, namely more comprehensive orientation for clinical educators, particularly around content and expectations of student performance. The results of this study are encouraging and we suggest that further, larger-scale investigation into models of simulation as replacement for clinical placement time is warranted, including greater engagement by the clinical educators in the simulation experience and more communication between the university and clinical educators about students' level of attainment before commencing clinical placement.

\section{Acknowledgements}

We wish to acknowledge the contributions of the following: Colleen Canning, Patricia McCabe, Kathryn Refshauge, Andrew Gonczi, Annie McCluskey, Victoria Neville, Belinda Judd, Louise Ada, Angela Stark, Carolyn Gates, Frances Moran, Zoe McKeough, Maree Milross, Christopher Gordon and The University of Sydney School of Nursing. This project was funded by a University of Sydney Strategic Teaching Enhancement Projects grant.

Conflict of interest: None declared

\section{Sources of funding}

None.

\section{ORCID}

Julia Blackford https://orcid.org/0000-0002-9596-5782

Jennifer Alison https://orcid.org/0000-0002-2011-4756

Lindy McAllister https://orcid.org/0000-0001-8715-3971

Gillian Nisbet $\quad$ https://orcid.org/0000-0001-5650-0280

\section{References}

Australian Physiotherapy Council. (2006). Australian standards for physiotherapy. Retrieved February 26, 2019, http://www.physiocouncil.com.au/australian_standards_for_physiotherapy/

Australian Physiotherapy Council. (2015). Physiotherapy practice thresholds in Australia and Aotearoa New Zealand. https://physiocouncil.com.au/wp-content/uploads/2017/10/Physiotherapy-BoardPhysiotherapy-practice-thresholds-in-Australia-and-Aotearoa-New-Zealand.pdf

Blackford, J., McAllister, L., \& Alison, J. (2015). Simulated learning in the clinical education of novice physiotherapy students. International Journal of Practice-based Learning in Health and Social Care, 3(1), 77-93. https://doi.org/10.18552/ijpblhsc.v3i1.209

Blackstock, F. C., Watson, K. M., Morris, N. R., Jones, A., Wright, A., McMeeken, J. M., Rivett, D. A., O'Connor, V., Peterson, R., Haines, T. P., Watson, G., \& Jull, G. A. (2013). Simulation can contribute a part of cardiorespiratory physiotherapy clinical education: Two randomized trials. Simulation in Healthcare, 8(1), 32-42. https://doi.org/10.1097/SIH.0b013e318273101a

Bokken, L., Rethans, J. -J., Scherpbier, A., \& van der Vleuten, C. (2008). Strengths and weaknesses of simulated and real patients in the teaching of skills to medical students: A review. Simulation in Healthcare, 3(3), 161-169. https://doi.org/10.1097/SIH.0b013e318182fc56

Chan, D. S. K. (2002). Associations between student learning outcomes from their clinical placement and their perceptions of the social climate of the clinical learning environment. International Journal of Nursing Studies, 39(5), 517-524. https://doi.org/10.1016/s0020-7489(01)00057-8 
Chipchase, L. S., Buttrum, P. J., Dunwoodie, R., Hill, A. E., Mandrusiak, A., \& Moran, M. (2012). Characteristics of student preparedness for clinical learning: Clinical educator perspectives using the Delphi approach. BMC Medical Education, 12(1), 112. https://doi.org/10.1186/1472-692012-112

Creswell, J. W., \& Plano Clark, V. L. (2011). Designing and conducting mixed methods research (2nd ed.). Sage.

Dalton, M., Davidson, M., \& Keating, J. (2011). The Assessment of Physiotherapy Practice (APP) is a valid measure of professional competence of physiotherapy students: A cross-sectional study with Rasch analysis. Journal of Physiotherapy, 57(4), 239-246. https://doi.org/10.1016/S18369553(11)70054-6

Dalton, M., Davidson, M., \& Keating, J. (2012) The Assessment of Physiotherapy Practice (APP) is a reliable measure of professional competence of physiotherapy students: A reliability study. Journal of Physiotherapy, 58(1), 49-56. https://doi.org/10.1016/S1836-9553(12)70072-3

Dutton, L., \& Sellheim, D. O. (2017). Academic and clinical dissonance in physical therapist education: How do students cope? Journal of Physical Therapy Education, 31(1), 61-72. https://doi.org/10.1097/00001416-201731010-00009

Gordon, J., Wilkerson, W., Shaffer, D. W., \& Armstrong, E. G. (2001). 'Practicing' medicine without risk: Students' and educators' responses to high-fidelity patient simulation. Academic Medicine, 76(5), 469-472. doi: https://doi.org/10.1097/00001888-200105000-00019

Houghton, C. E., Casey, D., Shaw, D., \& Murphy, K. (2013). Students' experiences of implementing clinical skills in the real world of practice. Journal of Clinical Nursing, 22(13-14), 1961-1969. https://doi.org/10.1111/jocn.12014

Hyde, E. (2015). A critical evaluation of student radiographers' experience of the transition from the classroom to their first clinical placement. Radiography, 21(3), 242-247. https://doi.org/10.1016/j.radi.2014.12.005

Jette, D. U., Bertoni, A., Coots, R., Johnson, H., McLaughlin, C., \& Weisbach, C. (2007). Clinical instructors' perceptions of behaviors that comprise entry-level clinical performance in physical therapist students: A qualitative study. Physical Therapy, 87(7), 833-843. https://doi.org/10.2522/ptj.20070003

Kneebone, R., \& Nestel, D. (2005). Learning clinical skills - The place of simulation and feedback. The Clinical Teacher, 2(2), 86-90. https://doi.org/10.1111/j.1743-498X.2005.00042.x

Kneebone, R. L., Scott, W., Darzi, A., \& Horrocks, M. (2004). Simulation and clinical practice: Strengthening the relationship. Medical Education, 38(10), 1095-1102. https://doi.org/10.1111/j.1365-2929.2004.01959.x

Moore, D. S. (1999). The basic practice of statistics (2nd ed.). W.H. Freeman.

National Health Workforce Taskforce (2008). Health education and training. Clinical placements across Australia: Capturing data and understanding demand and capacity. Retrieved February 26, 2019, http://www.ahwo.gov.au/publications.asp

Patton, M. (2002). Qualitative research and evaluation methods (3rd ed.). Sage.

Watson, K., Wright, A., Morris, N., McMeeken, J., Rivett, D., Blackstock, F., Jones, A., Haines, T., O'Connor, V., Watson, G., Peterson, R., \& Jull, G. (2012). Can simulation replace part of clinical time? Two parallel randomised controlled trials. Medical Education, 46(7), 657-667. https://doi.org/10.1111/j.1365-2923.2012.04295.x 
Wright, A., Moss P., Watson K., \& Rue, S. (2015). Simulation in physiotherapy clinical training: Final report. Department of Health.

http://lamp.physio.curtin.edu.au/simproj/HWA\%20Embedding\%20Simulation\%20in\%20Clinica 1\%20Physiotherapy\%20Final\%20Report.pdf 